\title{
EQUINE OCULAR SETARIASIS AND ITS MANAGEMENT
}

\section{Malik Abu Rafee* and Amarpal}

Division of Surgery and Radiology, Indian Veterinary Research Institute, Izatnagar, Bareilly, U.P India-243122

Received - October 15, 2016; Revision - November 02, 2016; Accepted - November 21, 2016

Available Online-December 04, 2016

DOI: http://dx.doi.org/10.18006/2016.4(Spl-4-EHIDZ).S139.S143

\begin{abstract}
KEYWORDS
Ocular setariasis

Eye worm

Equine

Surgery

ABSTRACT

Ocular setariasis is a common vision threatening ophthalmic condition in equine resulting from ectopic parasitism by Setaria digitata, Setaria equina and Thelazia lacrymalis. The disease occurs mostly in summer and autumn seasons and it displays signs of lacrimation, photophobia, corneal opacity, conjunctivitis and loss of vision. Close inspection of the eye reveals a moving worm in the anterior chamber of the eye. B-mode (brightness mode) ultrasonography helps in the diagnosis in case of complete opacity. The best treatment is the surgical removal of the parasite under regional/ general anesthesia. Needle paracentesis at $3 \mathrm{O}^{\prime}$ clock and nick incision at $12 \mathrm{O}^{\prime}$ clock position are most commonly used surgical procedure. Both the techniques give good results. A slightly modified technique of using a 21 gauge needle attached with the syringe to aspirate the worm into the syringe also gives satisfactory results. In medicinal therapy ivermectin is the most advocated drug for ocular equine setariasis, but long term tying of medicinal should be avoided and surgery should be advocated. Corneal opacity is the most common post operative complication reported. Post surgical use of placentrex has also been advocated to enhance healing and to resolve corneal opacity. The present review is aimed at etiology, diagnosis and management of ocular setariasis in equine species.
\end{abstract}

* Corresponding author

E-mail: rafee188@gmail.com (Malik Abu Rafee)

Peer review under responsibility of Journal of Experimental Biology and Agricultural Sciences.

Production and Hosting by Horizon Publisher India [HPI] (http://www.horizonpublisherindia.in/).

All rights reserved.
All the article published by Journal of Experimental Biology and Agricultural Sciences is licensed under a Creative Commons Attribution-NonCommercial 4.0 International License Based on a work at www.jebas.org.

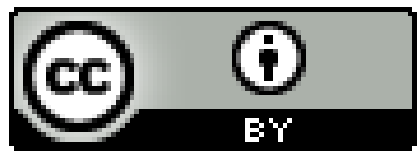




\section{Introduction}

Among the most common surgical conditions of equine ocular setariasis is a vision threatening disease of equine resulting from ectopic parasitism caused by Setaria spp, a genus of filaroid worms (Gangwar et al., 2008; Radwan et al., 2016). In India equine ocular setariosis, an important cause of corneal opacity is commonly caused by Setaria digitata, Setaria equina and Thelazia lacrymalis (Sathu, 1974; Ladoucer \& Kazacos, 1981; Parrah et al., 2004; Sellon \& Long, 2013). S. digitata is a parasite of cattle and hoofed animals and is found mainly in Asia. S. equina infects horses and other equids worldwide. The usual predilection site of adult Setaria worms is the peritoneal cavity. Occasionally they can get into the central nervous system or the eyes (Yadav et al., 2006). Microfilariae (immature larvae) are found in the blood. The parasite is transmitted by mosquitoes (Anopheles peditaneniatus and Culex nilgiricus) through the blood stream. Adult female worms release microfilariae in the abdominal cavity of their hosts. These microfilariae get into the blood stream and reach the capillaries in the skin. Mosquitoes become infected with microfilariae when they feed blood of infected hosts that contains microfilariae. These microfilariae develop to infective larvae inside the mosquitoes in 2 to 3 weeks. The infected mosquitoes then transmit these infective larvae to other susceptible hosts during their blood meals.

The ocular setariasis spreads mostly in summer and autumn when the mosquito vectors are most prevalent (Mritunjay et al., 2011; Al-Azawi et al., 2012). The parasite exhibits migratory behavior in unusual hosts such as horses, donkeys or human beings and can be found in various organs such as heart, lung, spleen, kidney, uterus, oviduct, ovary, and urinary bladder (Varma et al., 1971). All equines are generally more prone for ocular worm (Pratap, et al., 2005; Jayakumar et al., 2012; Radwan et al., 2016). The immature worm can also invade eye (Sreedevi et al., 2002; Tuntivanich et al., 2011) through the vascular system (Townsend, 2013). The eye infection occurs when the adult worm meanders through intraocular tissue, thus it is also called as eye worm.

The infected animals usually display signs of photophobia and lacrimation (Basak et al., 2007). The serrated cuticle of the worm and lashing movements within the anterior chamber of the eye caused severe trauma and inflammation to the cornea which then results into corneal opacity, which eventually results into blindness (Jaiswal et al., 2006). Basak et al. (2007) has reported corneal edema caused by dead filarial worm attachment to the endothelium in the anterior chamber. The dead worm possibly liberates toxins into the anterior chamber, which may be lethal to the endothelium and resulting into corneal edema. It may lead to devastating sequel like synechia, cataract, and retinal detachment (Paglia et al., 2004). Though, the involvement of the eye is commonly unilateral but bilateral occurrence has also been reported (Shin et al., 2002; Buchoo et al., 2005).

\section{Diagnosis}

Lacrimation, photophobia, blepharospasm and corneal opacity are the common signs seen in horses with eye worm. Keen inspection of the eye usually reveals moving worm in the anterior chamber of the eye. The affected eye reacts to bright flash stimulus and fluorescein staining test is usually negative, whereas slit-lamp biomicroscopic examination reveals corneal edema (Tuntivanich et al., 2011). In eyes with complete corneal opacity B-mode ultrasonography $(12 \mathrm{MHz}$, corneal contact technique) can be performed to visualize the anterior chamber and other intraocular structures (Patil et al., 2012). Though CBC (complete blood count) does not show major changes but a decrease in erythrocyte count, haemoglobin and haematocrit, together with leucocytosis and an accelerated erythrocyte sedimentation rate (ESR) has been reported in previous studies (Muhammad \& Saquib, 2007). Microscopic examination of wet blood films is also recommended as it sometimes reveals motile microfilariae. Knott's test (a technique for the detection of microfilariae by haemolysis and concentration of blood samples) can be performed to detect the microfilariae of the Setaria species (Slim \& Fouad, 1965).

\section{Surgical treatments}

Although both medical and surgical treatments have been advocated for the equine ocular filariasis (Muhammad \& Saquib, 2007), the best treatment is the surgical removal of the parasite (Tuntivanich et al., 2011) that can be performed under general anesthesia or regional nerve blocks with or without sedation. Regional nerve blocks like supraorbital, auriculopalpebral and retrobulbar can be performed using $2 \%$ lidocaine as per the standard methods described in literature (Lumb \& Jones, 2001). Akinesis of the eyelids can further be achieved by blockade of the ventral and dorsal branches of the palpebral nerve (Facial VII) (Skarda, 1996).

The supraorbital nerve is desensitised as it emerges from the supraorbital foramen, which is easily palpated $1 \mathrm{~cm}$ caudal to the upper orbital rim, 5-7 cm dorsal to the medial canthus. By using a 23-25 gauge needle, 1-3 ml lidocaine can be injected subcutaneously and into the foramen. This desensitises the forehead and the middle two-thirds of the upper eyelid. Motor paralysis of the auriculo-palpabral nerve (VII) is achieved by perineural administration of local anesthetics to this nerve at the most dorsal point of the zygomatic arch or just caudal to the vertical ramus of the mandible, just ventral to the zygomatic arch. The retrobulbar block may be achieved using a 19 gauge $80 \mathrm{~mm}$ long spinal needle passed over the zygomatic arch in a ventro-medial direction until it encounters the medial wall of the bony orbit (Fletcher, 2004; Labelle \& Clark-Price, 2013). The cornea and sclera may be desensitised most effectively spraying topical application of $1 \%$ solution of amethocaine (Durham et al., 1992) or $1 \%$ tropicamide (McMullen et al., 2014). 
Surgical interventions used for the treatment of ocular setariasis include needle paracentesis at 3 O' clock (Sreedevi et al., 2002; Vadalia, 2013) and nick incision at 12 O' clock (Buchoo et al., 2005). Prior to surgery, it is better that horses should receive topical non-steroidal anti-inflammatory agent (0.3\% flurbiprofen) along with systemic non-steroidal antiinflammatory agents (flunixin meglumine or ketoprofen) and antibiotics. For preparation of the eye for surgery topical antiseptic (like $0.5 \%$ betadine) can be used (Patil et al., 2012). The head is held in still position with a twitch. Eye lids are retracted with the Castroviejo eye speculum and a stab incision is made at 12 O' clock with BP blade No. 11 (Buchoo et al., 2005). The parasite usually gets ejected along with the aqueous humor; however, sometimes the parasite gets stuck in the incision. In such cases the worm is removed with the help of forceps.

The incision is left unsutured. Dorsal and lateral approaches allow monitoring of the incision postoperatively and at the same time does not create the potential for possible suture trauma associated with excursions of the nictitating membrane (Kalpravidh et al., 1992). However, when additional protection of wound by nictitating membrane is required a stab incision at the ventral margin of limbus is preferred (Patil et al., 2012). The use of viscoelastic substance like hypromellose is injected into the anterior chamber to decelerate the vigorous movement of the worm to facilitate the removal of the worm (Patil et al., 2012).

In the second method, a 16 gauge needle is inserted into the anterior chamber of the eye at 3 O' clock position (Sreedavi et al., 2002) or at 6-8 O' clock (Gopinathan et al., 2013) position of the cornea, approximately $1 \mathrm{~mm}$ away from the limbus, as soon as the worm appear near this site. Due to the aqueous humor pressure, the eye worm usually escapes through the hub of the needle or it appears at the puncture site thereby facilitating removal. Aqueous humor leakage is minimal as the needle puncture hole is very small (Gopinathan et al., 2013). In a slightly modified needle technique a 21 gauge needle attached with the syringe is inserted through the conjunctiva into the anterior chamber and directed carefully towards the worm to aspirate the worm into the syringe (Yang et al., 2014). The puncture site is left without suturing. Needle stabbing technique, is economical, time saving and recommended for the removal of parasite (Singh et al., 1976). Postoperatively sub-conjunctival injection of dexamethasone (2 $\mathrm{mg})$ gentamicin (20 mg) may be given. Topical application of ofloxacin or other eye ointment is considered.

Corneal opacity at the site of stab incision is the most common postoperative complication reported (Sharma et al., 2005). Sometimes it diffuses to involve the whole upper quadrant (Patil et al., 2012). This takes days to 3 to 8 weeks to get resolved (Buchoo et al., 2005; Jaiswal et al., 2006; Patil et al., 2012). Human placenta extract has anti-inflammatory and analgesic effects and enhance wound healing (Piyali \& Debasish, 2012; Changole et al., 2015; Shukla et al., 2016).
Placentrex facilitate post surgical healing at the insertion site in equine ocular setariasis (Mritunjay et al., 2011).

\section{Medicinal therapies}

Taking in consideration complications of surgical treatment like phthisis bulbi, corneal oedema, and scarring and prolapse of the iris (Lavach, 1990), various medicinal therapies have been advocated. However, Medical treatment has not been considered suitable because of the slow absorption of dead parasites and the attendant antigenicity (Moore et al., 1983; Lavach, 1990). The standard antifilarial drug, diethylcarbamazine citrate (DEC) has given inconsistent results (Perumal \& Seneviratna, 1954; Ahmad \& Gupta, 1965). Also, an inconveniently large number of repeat treatments (for example, 32 treatments over 45 days) (Razig, 1989) has precluded DEC as a practical chemotherapeutic agent for equine setariasis. Muhammad \& Saquib (2007) have advocated a medicinal therapy for ocular equine microfilariasis using ivermectin and death of the parasite in the eye took 15 days after administration of ivermectin. These suggested that in situations in which surgical intervention is difficult, the offlabel use of ivermectin would be appropriate to treat ocular equine setariasis.

\section{Conclusion}

Ocular setariasis commonly known as eye worm is a common surgical condition of equine eye affecting horse, donkey and pony equally. The condition can be easily diagnosed on the basis of clinical symptoms like lacrimation, photophobia, blepharospasm, corneal opacity and visible worm in the anterior chamber of the eye. Surgical treatment under regional/ general anesthesia is an effective treatment of the condition. Though, medicinal therapy with ivermectin is advocated, however relying on the medicinal treatment for too long should be avoided. Ophthalmic ointments decreasing inflammation and chances of infection and/or enhancing the healing can be used to reduce the chances of postsurgical complication.

\section{Conflict of interest}

Authors would hereby like to declare that there is no conflict of interests that could possibly arise.

\section{References}

Ahmad SA, Gupta BN (1965) Filaria oculi in equines: a therapeutic trial with the filaricidal drug Hetrazan (diethylcarbamazine citrate) Lederle. Indian Veterinary Journal 42:140-142.

Al-Azawi AK, Fadhl AR, Fadhl SR (2012) Epidemiological study of Setaria equina infection in donkeys. Iraq Veterinary Journal 36 : 93-97. 
Basak SK, Hazra TK, Bhattacharya D (2007) Persistent corneal edema secondary to presumed dead adult filarial worm in the anteriorchamber. Indian Journal of Ophthalmology 55: 67-69. DOI: 10.4103/0301-4738.29501.

Buchoo BA, Pandit BA, Shahardar RA, Parrah JD, Darzi, MM (2005) Surgical management and prevalence of ocular filariasis in equines. Indian Veterinary journal 82: 81-82.

Changole S, Gupta B, Nandagawali V, Palyekar A, Chipde H (2015) Comparative Study of Efficacy of Human Placental Extract Over Beta Glucan Collagen Sheets in Partial Thickness Burn Patients. Bombay Hospital Journal 57 : 279-284.

Durham RA, Sawyer DC, Keller WF, Wheeler CA (1992) Topical ocular anesthetics in ocular irritancy testing: a review. Laboratory animal Sciences 42: 535-541.

Fletcher BW (2004) How to perform effective equine dental nerve blocks. Proceeding of American Association of equine Practioners 50: 233-239.

Gangwar AK, Devi S, Singh HN, Singh A (2008) Ocular filariasis in equines. Indian Veterinary Journal 85: 547-548.

Gopinathan A, Singh K, Saxena AC, Khurana KL, Amarpal (2013) Evaluation of two techniques for management of ocular Setariasis in horses. Research Opinion in Animal and Veterinary Sciences $3:$ 407-411.

Jaiswal S, Singh SU, Singh B, Singh HN (2006) Ocular setariosis in a horse. Intas Polivet 7: 67-68.

Jayakumar K, Dharmaceelan S, Rajendran N, Senthilkumar S, Kathirvel S, Nagarajan L, Kumaresan A (2012) Ocular Setariasis in a Pony. Indian Veterinary Journal $89: 64-66$.

Kalpravidh M, Bramasa A, Kalpravidth C (1992) Surgical removals of intraocular parasites from the anterior chambers of the horse eyes. Thailand Journal of Veterinary Medicine 22: 13-20.

Labelle AL, Clark-Price SC (2013) Anesthesia for Ophthalmic Procedures in the Standing Horse. Veterinary Clinics of North America: Equine Practice 29 : 179-191. doi: 10.1016/j.cveq.2012.12.001.

Ladoucer CA, Kazacos KR (1981) Thelazia lacrimalis in horses in India. Journal of American Veterinary Medical Association 178: 301-302.

Lavach JD (1990) Parasitic diseases. In Large Animal Ophthalmology. Vol 1. Philadelphia, Mosby pp 260-263.

Lumb WV, Jones EW (2001) Local and regional anesthetic and analgesic techniques. In: Veterinary anesthesia, 3rd ed. Lea and Febiger, Philahelphia pp 449.
McMullen RJ Jr1, Davidson MG, Gilger BC (2014) The effect of $1 \%$ tropicamide-induced mydriasis and cycloplegia on spherical refraction of the adult horse. Veterinary Ophthalmology 17 : 120-125. doi: 10.1111/vop.12055.

Moore CP, Sarazan RD, Whitley RD, Jackson WF (1983) Equine ocular parasites: a review. Equine Veterinary Journal Supplement 2:76-85. DOI: $\quad 10.1111 / \mathrm{j} .2042-$ 3306.1983.tb04565.x.

Mritunjay K, Monsang SW, Pawde AM, Singh SK, Madhu DN, Zama MMS (2011) Post surgical healing effect of placentrex in equine (Equus cabalus) ocular setariasis: A review of 22 cases. The Indian Journal of Field Veterinarians 6: 71-73.

Muhammad G, Saqib M (2007) Successful treatment of ocular equine microfilariasis (Setaria species) with ivermectin. Veterinary Record 160: 25-26.

Paglia DT, Miller PE, Dubielzig RR (2004) James Wardrop and equine recurrent uveitis. Archives of ophthalmology 122:1218-1223. doi:10.1001/archopht.122.8.1218.

Parrah JD, Buchoo BA, Moulvi BA (2004) Ocular filariasis in equines. A study of 9 cases. Centaur 4: 70-71.

Patil DB, Parikh PV, Nisha J, Jhala SK, Din DMU,Tiwari DK (2012) Equine eye worm: a review of 50 cases. Indian Journal of Veterinary Surgery 33: 61-62.

Perumal PC, Seneviratna P (1954) Kumri (Syn: Kamri) in horses associated with ocular setariasis with a short note on attempted treatment. Ceylon Veterinary Journal 2:92-94.

Piyali DC, Debasish B (2012) Aqueous Extract of Human Placenta. In: Zheng J (Ed.), Recent Advances in Research on the Human Placenta, InTech Publisher ISBN: 978-953-510194-9.

Pratap K, Amarpal A, Aithal HP, Pawde AM (2005) Survey of eye disorders in domestic animals. The Indian Journal of Animal Science 75:33-34.

Radwan AM, Ahmed NE, Elakabawy LM, Ramadan MY, Elmadawy RS (2016) Prevalence and pathogenesis of some filarial nematodes infecting donkeys in Egypt. Veterinary World 9 : 888-892. doi: 10.14202/vetworld.2016.888-892.

Razig SA (1989) A preliminary clinical trial on the use of diethylcarbamazine citrate for the treatment of equine filariasis. Acta Veterinaria (Belgrade) $38: 145-151$.

Sathu S (1974) Intraocular parasites in horses. A report of five cases. Indian Veterianary Journal 5: 225.

Sellon CD, Long M (2013) Equine Infectious Diseases. 2nd ed. Science Direct publication, St. Louis, MI. 
Sharma R, Shrivastava HK, Chauhan S, Kumar R (2005) Equine keratouveitis by Setaria spp. microfilaria and its management- A review of 14 cases. Intas Polivet 6: 260-261.

Shin S, Cho K, Wee SH (2002) Ocular infection of cattle with Setaria digitata. Journal of Veterinary Medical Science 64: 710.

Shukla AD, Kamath AT, Kudva A, Pai D, Patel N (2016) Our Experience in the Management of Traumatic Wound Myiasis: Report of 3 Cases and Review of the Literature. Case Reports in Dentistry. DOI:10.1155/2016/7030925.

Singh H, Chaudhuri PC, Kumar A (1976) Paracentesis oculi: a preferred technique for removal of intra-ocular parasites in horses. Indian Veterinary Journal 53: 467-468.

Skarda S (1996) Regional anaesthetic techniques In: Thurnon JC, Tranquilli WJ, Benson JG (Eds) Lumb and Jones' Veterinary Anesthesia, 3rd edn., Lea and Febiger, Baltimore. pp 448-477.

Slim MK, Fouad KA (1965) Incidence of equine filariasis in Egypt. Veterinary Medical Journal 10:113-118.

Sreedavi C, Sudhakar K, Murthy PR, Prasad V (2002) Clinical microfilariasis in a horse:a case report. Indian Veterinary Journal 79: 487-488.
Townsend WM (2013) Food and fiber-producing animal ophthalmology. In: Gelatt KN (Ed). Essentials of veterinary ophthalmology, 2nd ed., Wiley-Blackwell publication, UK, pp: 532. DOI: $10.1002 / 9781118910337$

Tuntivanich N, Tiawsirisup S, Tuntivanich P (2011) Success of Anterior Chamber Paracentesis as a treatment for Ocular Setariasis in Equine Eye: Case Report. Journal of Equine

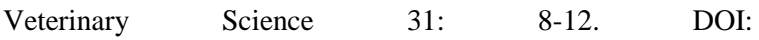
http://dx.doi.org/10.1016/j.jevs.2010.11.017.

Vadalia JV (2013) Surgical Treatment of Ocular Setariosis in a Stallion. The Indian Journal of Veterinary Science 13:11.

Varma AK, Sahai BN, Singh SP, Lakra P, Shrivastava VK (1971) On Setaria digitata, its specific characters, incidence and development in Aedes vittatus and Armigeres obturbans in India with a note on its ectopic occurrence. Zeitschrift für Parasitenkunde 36: 62-72. DOI: 10.1007/BF00328975.

Yadav A, Kumar A, Bhadwal MS, Khajuria JK, Gupta A (2006) Ocular setariosis in horses: A case study. Journal of Veterinary Parasitology $20: 1-10$.

Yang YJ, Cho YJ, Choi SK, Cho GJ (2014) Modified Needle Aspiration Technique for Extracting Live Eye Worm in a Thoroughbred Horse. Journal of Animal and Veterinary Advances 13: 998-1001. DOI: 10.3923/javaa.2014.998.1001. 